IZA DP No. 7989

The Effect of Renewable Energy Development on Carbon Emission Reduction:

An Empirical Analysis for the EU-15 Countries

Shahrouz Abolhosseini

Almas Heshmati

Jörn Altmann

February 2014 


\title{
The Effect of Renewable Energy Development on Carbon Emission Reduction: An Empirical Analysis for the EU-15 Countries
}

\author{
Shahrouz Abolhosseini \\ TEMEP, Seoul National University \\ Almas Heshmati \\ Sogang University \\ and IZA \\ Jörn Altmann \\ TEMEP, Seoul National University
}

Discussion Paper No. 7989

February 2014

IZA

P.O. Box 7240

53072 Bonn

Germany

Phone: +49-228-3894-0

Fax: +49-228-3894-180

E-mail: iza@iza.org

Any opinions expressed here are those of the author(s) and not those of IZA. Research published in this series may include views on policy, but the institute itself takes no institutional policy positions. The IZA research network is committed to the IZA Guiding Principles of Research Integrity.

The Institute for the Study of Labor (IZA) in Bonn is a local and virtual international research center and a place of communication between science, politics and business. IZA is an independent nonprofit organization supported by Deutsche Post Foundation. The center is associated with the University of Bonn and offers a stimulating research environment through its international network, workshops and conferences, data service, project support, research visits and doctoral program. IZA engages in (i) original and internationally competitive research in all fields of labor economics, (ii) development of policy concepts, and (iii) dissemination of research results and concepts to the interested public.

IZA Discussion Papers often represent preliminary work and are circulated to encourage discussion. Citation of such a paper should account for its provisional character. A revised version may be available directly from the author. 


\section{ABSTRACT \\ The Effect of Renewable Energy Development on Carbon Emission Reduction: An Empirical Analysis for the EU-15 Countries}

The increased concerns about climate change have made renewable energy sources an important topic of research. Several scholars have applied different methodologies to examine the relationships between energy consumption and economic growth of individual and groups of countries and to analyze the environmental effects of energy policies. Previous studies have analyzed carbon emission savings, using renewable energy usage as an individual source or in combination with traditional sources of energy (e.g., hybrid plants) in connection with lifecycle analysis methods. It is shown that after a certain period, economic growth leads to the promotion of environmental quality. However, econometric modelling critiques have opposed the results of these studies. One reason is that the effectiveness of governance-related parameters has previously been neglected. In this research, we analyze the impact of renewable energy development on carbon emission reduction. We estimate a model to evaluate the effectiveness of renewable energy development, technological innovation, and market regulations in carbon emission reduction. The empirical results are based on a panel data estimation using the EU-15 countries data observed from 1995 to 2010. The elasticities of $\mathrm{CO}_{2}$ emissions are estimated, in order to evaluate the effectiveness of each parameter. The findings show that the effects of a negative climate change could be mitigated by governance-related parameters instead of economic development.

JEL Classification: D62, H23, N50, O13, O14

Keywords: renewable energy, technological innovation, environmental tax, carbon emission, economic growth

Corresponding author:

Almas Heshmati

Department of Economics, Room K526

Sogang University

35 Baekbeom-ro (Sinsu-dong \#1)

Mapo-gu, Seoul 121-742

Korea

E-mail: heshmati@sogang.ac.kr 


\section{Introduction}

During the last three decades, two different approaches have been applied in the research of natural resources. The first approach is based on the viewpoint that considers the effect of natural resources on economic growth. Many researchers have studied the relationship between energy consumption and economic growth. Early studies were published in the 1970s, including Allen et al. (1976), Hitch (1978), and Kraft and Kraft (1978). This relationship has been studied in both individual and groups of countries. Akarca and Long (1980), Yu and Hwang (1984), Cheng (1995), and Stern (2000) applied this methodology in the US. Wold-Rufael (2005) employed the causal relationship methodology in a study of 19 African countries. Lee and Chang (2007) tested causality in 16 Asian countries, while Huang et al. (2008) tested causality in 82 countries. The effect of energy consumption on economic growth differs substantially in developed countries. Narayan and Prasad (2007) found different causality effects in 30 OECD countries. This means that conservative energy policy could affect individual countries differently.

The second approach takes into account the environmental effects of economic growth. Following the empirical study of Grossman and Kruger (1991), many scholars analyzed the relationship between economic growth and environmental pollution. Coondoo and Dinda (2002) studied the relationship of income and $\mathrm{CO}_{2}$ emissions based on a Granger causality test of cross-country panel data. Zhang and Cheng (2009) investigated Granger causality among economic growth, energy consumption, and carbon emissions in China. Soytas and Sari (2009) examined causality relationships between these variables in Turkey. In a recent study, Choi et al. (2011) used the Environmental Kuznets Curve (EKC) to examine the relationship of carbon dioxide emissions with economic growth and openness.

In the present study, we investigate EKC according to a number of variables frequently used in empirical studies. The variables are: share of renewable energy sources in total power generated; number of patents per million inhabitants for energy applications adopted to mitigate climate change; ICT as a proxy variable for technological innovation; environmental tax per capita as a proxy variable for market regulation; and time trend. We examine the effects of these variables on carbon emission per capita.

Our contribution is the investigation of the effectiveness of power generated by renewable energy sources, technological innovation, and market regulations on the mitigation of climate change. We also calculate the elasticity of carbon emissions per capita for each parameter. The results obtained could be used by policy makers to evaluate effectiveness of different policy tools and the effects of interactions between these policies.

Rest of this study is organized as follows. Section 2 outlines the methodology and framework. The data, model specification, and estimation is discussed in Section 3. Section 4 presents the estimation result and its analysis. The final section concludes the paper with a final discussion. 


\section{Methodology and Analytical Framework}

In this section, we explain the methodology used to build the model. We explain the model specification and state the hypothesis of the model.

\subsection{Methodology}

A cross-country panel data model has been applied to EU-15 countries data. Hsiao (2003) and Klevmarken (1989) mentioned various advantages for using panel data, such as controlling for individual heterogeneity, more variability, less co-linearity among the variables, more degrees of freedom, and more efficiency (Baltagi, 2008). The countries differ in terms of economic structure, technology, and policy. If this heterogeneity is not accounted for, serious misspecifications could result. Moreover, the probability of co-linearity is high in time-series studies, but it is less likely with a panel data, because the cross-country dimension adds to variability. Additionally, informative data could lead to the increased reliability of estimators. Several different linear models can be applied to panel data. The model for the scalar dependent variable, $Y_{i t}$, is specified as:

$$
Y_{i t}=X_{i t} \beta^{\prime}+\alpha_{i}+\gamma_{t}+v_{i t}
$$

where $\alpha_{i}$ and $V_{t}$ are error components specific to units i and time periods t. The composite error term $u_{i t}=\alpha_{i}+\gamma_{t}+v_{i t}$ is generally not independent and identically distributed, but its variance-covariance matrix $(\Omega)$ could be estimated. $Y_{i t}$ is the $\mathrm{nx} 1$ matrix of a dependent variable, $X_{i t}$ is the $N x K$ matrix of independent variables, $\beta$ is the $K x 1$ matrix of unknown parameters to be estimated. Two different assumptions may be applied for $\alpha_{i}$ and $Y_{t}$ : fixedeffects and random-effects models (Johnston and DiNardo, 2007). In the fixed-effect (FE) model, $\boldsymbol{\alpha}_{i}$ and $\mathrm{Y}_{t}$ can be correlated with the independent variables, but it is assumed that $X_{i t}$ is uncorrelated with the error term $v_{i t}$. The attraction of the FE model is that it follows a consistent estimator (Cameron and Trivedi, 2009). The random-effect (RE) model assumes that $\alpha_{i}$ and $Y_{t}$ are random, and they are not correlated with the independent variables.

Based on the Gauss-Markov theorem, if the errors have an expectation of zero, are uncorrelated, and have equal variance, the least-square estimators (OLS) has minimum variance in the class of linear unbiased estimators. It is called the best linear unbiased estimator, or BLUE (Johnston and DiNardo, 2007). Therefore, if we have these assumptions:

$$
\begin{aligned}
& E(u \mid X)=0 \\
& E\left(u u^{\prime} \mid X\right)=\sigma^{2} \Omega
\end{aligned}
$$

In eq. 2, the disturbances have conditional zero mean. In eq. $3, \Omega=I_{N}$ is an $N x N$ identity matrix. It means that conditional on the $X$, the disturbances are independent and identically 
distributed with conditional variance $\sigma^{2}$ (Jackman, 2004) Then the ordinary least estimator $\hat{\beta}_{O L S}=\left(X^{\prime} X\right)^{-1} X^{\prime} Y$ with variance-covariance matrix $V\left(\hat{\hat{\beta}}_{O L S}\right)=\sigma^{2}\left(X^{\prime} X\right)^{-1}$ is BLUE. If the assumption in eq. 3 fails to hold, the mentioned estimator is unbiased but not BLUE. According to Johnston and DiNardo (2007), eq. 3 states that disturbances have homoscedasticity and are pair-wise uncorrelated. However, this condition is rarely satisfied in practice, so it is important to develop feasible generalized least square (FGLS) estimators, where unknown parameters are substituted by consistent estimates (Johnston and DiNardo, 2007).

It should be noted that when eq. 3 holds, $\Omega=I_{N}$ and $\hat{\beta}_{G L S}=\hat{\beta}_{O L S}$. Considering that we usually do not have knowledge of $\Omega, \hat{\beta}_{F G L S}$ is non-operational, and we have to utilize the FGLS estimator. FGLS estimators are calculated in three steps (Jackman, 2004): (i) OLS analysis to yield estimated residuals $\hat{u}$, (ii) analysis of the $\hat{u}$ to form an estimate of $\Omega$, and (iii) estimation of the FGLS estimator as $\hat{\beta}_{F G L S}=\left(X^{\prime} \hat{\Omega}^{-1} X\right)^{-1} X^{\prime} \hat{\Omega}^{-1} Y$.

FGLS is the most commonly used estimator in dealing with residual autocorrelation and heteroscedasticity. Cochrane-Orcutt (1949) and Paris-Winsten (1954) established procedures for $A R(1)$ disturbances yielding FGLS estimators. Judge et al. (1980) and Amemiya (1985) provided different rigorous treatments of FGLS estimators in this regard (Jackman, 2004).

\subsection{Model Specification}

We specify and estimate our model based on the Environmental Kuznets Curve (EKC). The Kuznets Curve was introduced, in order to show the relationship between inequality in the distribution of income and levels of income (Kuznets, 1955). However, in the 1990s, the curve became an engine for studying the relationship between emissions and economic growth. The standard form of this function is defined as follows (Grossman and Krueger, 1991):

$$
\ln (E / P)_{i t}=\alpha_{i}+\beta_{1} \ln (G D P / P)_{i t}+\beta_{2}\left(\ln (E / P)_{i t}^{2}\right)+\varepsilon_{i t}
$$

where $E$ is urban air pollution, $P$ is population, GDP is gross domestic product, and ln indicates natural logarithms. Several basic models have been estimated without additional independent variables (Grossman and Krueger, 1991; Shafik, 1992; Selden and Song, 1994). Many researchers have employed this model, by using additional explanatory variables, to evaluate the environmental effects of different factors. Panayotou (1993) examined the hypothesis of deforestation (DEF) as a function of income per capita (INC) and population density (POP) as follows:

$$
\begin{aligned}
\ln D E F_{i t}= & \alpha_{0}+\alpha_{1} \ln I N C_{i t}+\alpha_{2} \ln P O P_{i t}+1 / 2 \alpha_{11}\left(\ln P O P_{i t}\right)^{2}+1 / 2 \alpha_{22}\left(\ln I N C_{i t}\right)^{2} \\
& +\alpha_{12} \ln P O P_{i t} \ln I N C_{i t}+\varepsilon_{i t}
\end{aligned}
$$


A translog formulation is applied to allow for nonlinearity and interaction effects between explanatory variables and the evaluation of elasticities.

Some researchers investigated the effects on environmental quality of literacy, political rights, and civil liberties (Torras and Boyce, 1998), output structure (Panayotou, 1997), and trade (Suri and Chapman, 1998). Choi et al. (2011) employed trade dependence, fossil consumption per capita, share of renewable energy, and time trend in an attempt to broaden the concept of EKC and evaluate the impact of these parameters on $\mathrm{CO}_{2}$ emissions. Magnani (2000) used R\&D expenditure as a proxy to measure the impact of environmental protection on emissions.

In this study, we evaluate the impact of renewable energy deployment, technological innovation and market regulation on carbon emission reduction. Similar to Panayotou (1993), our model is also formulated in a translog functional form, in order to investigate the nonlinear interaction effects between variables and calculate elasticities. Our model also permits us to check the shape of the relationship between dependent variables and explanatory variables.

$$
\begin{aligned}
\ln Y_{i t}=\alpha_{0} & +\sum_{j} \beta_{j} \ln X_{j i t}+1 / 2 \sum_{j} \beta_{j j}\left(\ln X_{j i t}\right)^{2}+\beta_{t} t+1 / 2 \beta_{t t} \mathrm{t}^{2} \\
& +\sum_{j} \sum_{k} \beta_{j \mathrm{k}} \ln X_{j i t} \ln X_{k i t}+\sum_{j} \beta_{j t} \ln X_{j i t} t+\varepsilon_{i t}
\end{aligned}
$$

where the variable $\mathrm{Y}$ represents the dependent variables defined as carbon emission per capita $\left(\mathrm{CO}_{2} / \mathrm{P}\right), X$ represents a vector of independent variables, including gross domestic product per capita (GDP/P), share of electricity generated by renewable energy sources in total power generation (Ren/TPG), number of energy-related patents per million inhabitants (Pateng/P), number of ICT patents per inhabitant (Patict/P), environmental tax per capita (Evt/P), and $t$ is the trend $(\mathrm{t})$ representing the rate of technical change in the $\mathrm{CO}_{2}$ function over time.

\subsection{Analytical Framework for Variable Selection}

Considering the long lifetime of $\mathrm{CO}_{2}$ in the atmosphere, stabilizing the concentration of greenhouse gases (GHGs) at any level depends on large reductions of worldwide $\mathrm{CO}_{2}$ emissions from current levels (IEA, 2012a). Therefore, $\mathrm{CO}_{2}$ emission reduction could be used as an index to evaluate climate change mitigation. In our model, $\mathrm{CO}_{2}$ emission is considered a dependent variable, and it is defined as total carbon dioxide emissions caused by the consumption of energy. The explanatory variables are defined as follows:

Gross domestic product (GDP): There is an extensive literature about the relationship between economic growth, energy consumption, and environmental pollution (Schmalensee, 2012; and Bartelmus, 2013).

Renewable energy sources: We used share of electricity produced by renewable energy sources (Ren) in total power generation (TPG) in our model. This is in line with the literature on the effectiveness of renewable energy sources in climate change mitigation (Sinha, 1995; 
Frankl et al., 1997; Schleisner, 2000; Lehner et al., 2005; Benitez et al., 2008; Saner et al., 2010. Renewable energy sources include biomasses, hydro, geothermal, solar, wind, ocean thermal, wave action, and tidal action (EIA, 2013).

Energy patent applications: Innovation has responded to the changes in expenditure for emission abatement over time (Lanjouw and Mody, 1996; Popp, 2003). Innovation is exhibit through energy efficiency ( $\mathrm{Li}$ and Colombier, 2009) and technological change in renewable energy capacity (Popp et al., 2011). Therefore, considering that technological innovation plays an important role in mitigating the effects of environmental problems, we added the number of energy technologies patents (Pateng) to the model.

ICT patent applications: Energy efficiency is a solution used to reduce carbon emissions. Different technologies could be used for this purpose. Besides electric vehicles (Ford, 1995; Kempton and Letendre, 1997; Kempton and Tomic, 2005), virtual power plants (Pudjianto et al., 2007; Ruiz et al., 2008; Jansen et al., 2010), and smart meters (Hartway et al., 1999; Faruqui, 2007; Depuru et al., 2011), ICT is a significant technology as it is a part of many technologies. The number of ICT patent (Patict) applications to the European Patent Office is employed as another kind of technological innovation indicator in our model.

Environmental tax: Environmental tax (Evt) is used as a proxy for market regulation, in order to evaluate its impact on carbon emission reduction. Finland and Sweden are in the forefront of taxing fuels because of environmental damage (Bhattacharyya, 2011). In line with the literature and based on the findings (Alfsen et al., 1995; Brännlund and Nordström, 2004; Galinato and Yodar, 2010), environmental tax is used as an explanatory variable. Total environmental taxes are for energy products, pollution, and natural resources.

Trend: Time trend represents the possibility that technological change causes shifts in the environment function over time (Shafik and Bandyopadhyay, 1992; Cole et al., 1997; Luzzati and Orsini, 2009). It is expected that the $\mathrm{CO}_{2}$ function shifts downwards, suggesting progress or reduction in $\mathrm{CO}_{2}$ over time for given energy use and GDP production. The inclusion of trend squared and its interaction with explanatory variables allows testing for the nonlinearity and non-neutrality of the changes in the $\mathrm{CO}_{2}$ function.

Fossil fuel energy is a major source of $\mathrm{CO}_{2}$ emissions. However, this variable is not used in order to avoid the co-linearity problem. Considering that we have employed GDP in our model, the related effects could be captured through this variable. Fossil fuel is the major source of primary energy consumption in EU-15. If fossil fuel consumption is used as an independent variable in our model, we may have co-linearity between GDP and fossil fuel consumption.

The translog formulation allows examining the interactions among the variables and their potential effects. For example, an increase in environmental compliance cost could lead to increases in the patenting of new environmental technologies (Jaffe and Palmer, 1997). Therefore, they could have an interaction effect on carbon emission reduction. According to Stern (1998), the use of resources implies the production of waste. In order to comply with 
Stern's comment, we apply a flexible translog functional form to allow for interaction effects.

\subsection{Hypotheses}

We define three hypotheses. First, the power generated by renewable energy sources in the EU-15 has been able to affect carbon emission by displacing traditional capacity fueled through fossil fuels. We also expect negative elasticity for renewable energy sources regarding carbon emission. (Note, elasticity, or the derivative of a variable y with respect to a variable $\mathrm{x}$, is defined as a measure of how changing one independent variable $\mathrm{x}$ affects the dependent variable $\mathrm{y}$, assuming all other independent variables are constant.) Second, technological advances are able to decrease the costs of renewable energy technologies and energy efficiencies, thereby saving energy and reducing carbon emissions. Therefore, we expect a negative relation between technological innovation and carbon emission. Furthermore, we expect negative elasticity for technological innovation, represented by a time trend. Finally, environmental tax applied by governments has a direct negative relation to carbon emissions. The size of this parameter could indicate its importance, compared with renewable energy development and technological innovation. We also expect a negative elasticity for environmental tax. The answers to these hypotheses help countries to make appropriate decisions to achieve targets for carbon emission reduction.

\section{Data, Model and Estimation}

In this section, we compare our proposed model with two other forms of function formulation and evaluate it by testing the functional form, model specification, and significance of the parameters. We then analyze the results and parameters.

\subsection{Data}

The data for this research on the effects of renewable energy development, technological innovation, and market regulation on carbon emission reduction is based on the EU-15 countries. ${ }^{1}$ These countries are selected because they are at the forefront of renewable energy development and have applied market regulation to mitigate climate change. In 1990, Finland was the first country to introduce a carbon tax, followed by Norway, Sweden and Denmark in 1992 (Bhattacharyya, 2011). Germany’s renewable sector is considered the most innovative and successful in the world. Since starting negotiations about climate change in 1991, the EU has provided leadership in global climate policy (Oberthür and Kelly, 2008).

These countries are studied during the period from 1995 to 2011. The impact of the financial crisis began in 2008, thus the pre- and post-crisis period can be compared. Different sources

\footnotetext{
1 The sample include Austria, Belgium, Germany, Denmark, Spain, Finland, France, Greece, Ireland, Italy, Luxembourg, Netherlands, Portugal, Sweden, and the UK.
} 
are used to obtain the necessary information for the model specification. The data on carbon emission, total power generation, and electricity produced by renewable energy sources was obtained from the US Energy Information Administration (EIA, 2013) database. The information related to environmental tax and the number of patent applications in energy technology and ICT was derived from the European Commission database (Eurostat). Population sizes were extracted from the World Bank database. Table 1 shows the summary, including the definition and sources of data for the explanatory variables $\mathrm{CO}_{2} / \mathrm{P}$ (CDECAP), GDP/P (GDPCAP), Ren/TPG (REGENP), Pateng/P (PTGCAP), Patict/P (PTICAP), Evt/P (EVTCAP), and TREND, where $\mathrm{P}$ indicates population resulting in per capita measures.

As the variables are measured in different units, the continuous variables are transformed to logarithmic form. The coefficients are interpreted directly as elasticities based on the percentage of changes. Regarding the units of measurement, the same unit was used for the explanatory variables. GDP per capita and environmental tax per capita were measured by a constant US dollar (2005). They were normalized by the deflator index. The measurement of the energy patents and ICT technologies are based on the number of patents per million inhabitants.

Table 1. Summary of the variables, their definitions, and data sources

\begin{tabular}{|c|l|l|}
\hline Variable & Definition & Source \\
\hline CDECAP & $\begin{array}{l}\text { Carbon dioxide emissions per capita generated by fossil fuels burning } \\
\text { and the cement manufacturers. } \mathrm{CO}_{2} \text { generated by consumption of solid, } \\
\text { liquid, and gas fuels, (gas flaring is included) The unit is in metric ton } \\
\text { per capita. }\end{array}$ & WB \\
\hline REGENP & $\begin{array}{l}\text { Share of electricity produced by renewable energy sources in total } \\
\text { power generation. }\end{array}$ & EIA \\
\hline GDPCAP & $\begin{array}{l}\text { GDP per capita based on the } 2005 \text { constant dollar. The unit is 1000 } \\
\text { USD per capita. }\end{array}$ & WB \\
\hline PTGCAP & $\begin{array}{l}\text { Number of patents in energy technologies or applications for mitigation } \\
\text { or adaptation against climate change per million inhabitants. }\end{array}$ & Eurostat \\
\hline PTICAP & Number of patents in ICT per million inhabitants. & Eurostat \\
\hline EVTCAP & $\begin{array}{l}\text { Total environmental tax per capita based on the 2005 constant dollar, } \\
\text { including: energy products, transport, and pollution. The unit is in } \\
\text { \$1000 per capita. }\end{array}$ & Eurostat \\
\hline TREND & Time trend & \\
\hline
\end{tabular}

Table 2 displays the correlation matrix for the variables presented in Table 1. If an explanatory variables shows a high correlation (higher than 0.50) with another, it should be omitted or redefined in order to avoid co-linearity and confounded effects. As the covariance matrix shows, no significant correlation was found between the explanatory variables. 
Table 2. Correlation matrix between explanatory variables (p-values in parenthesis)

\begin{tabular}{|l|c|c|c|c|c|c|c|}
\hline & CDECAP & GDPCAP & REGENP & PTGCAP & PTICAP & EVTCAP & TREND \\
\hline \multirow{2}{*}{ CDECAP } & 1.0000 & & & & & & \\
& & & & & & & \\
\hline \multirow{2}{*}{ GDPCAP } & 0.7085 & 1.0000 & & & & & \\
& $(0.000)$ & & & & & & \\
\hline \multirow{2}{*}{ REGENP } & 0.0 .640 & 0.1642 & 1.0000 & & & & \\
& $(0.323)$ & $(0.011)$ & & & & & \\
\hline \multirow{2}{*}{ PTGCAP } & 0.1441 & 0.4685 & 0.0715 & 1.0000 & & & \\
& $(0.026)$ & $(0.000)$ & $(0.269)$ & & & & \\
\hline \multirow{2}{*}{ PTICAP } & 0.0516 & 0.0843 & -0.1138 & 0.1087 & 1.0000 & & \\
& $(0.426)$ & $(0.193)$ & $(0.078)$ & $(0.093)$ & & & \\
\hline \multirow{2}{*}{ EVTCAP } & 0.1798 & 0.2749 & -0.0876 & 0.3829 & 0.0934 & 1.0000 & \\
& $(0.005)$ & $(0.000)$ & $(0.176)$ & $(0.000)$ & $(0.149)$ & & \\
\hline \multirow{2}{*}{ TREND } & 0.0017 & 0.3479 & -0.0661 & 0.3472 & 0.0283 & 0.1517 & 1.0000 \\
& $(0.979)$ & $(0.000)$ & $(0.308)$ & $(0.000)$ & $(0.662)$ & $(0.019)$ & \\
\hline
\end{tabular}

The sign for some variable pair coefficients such as $\mathrm{CO}_{2}$ emission per capita and GDP per capita (CDECAP-GDPCAP), environmental tax per capita and number of energy patent per million inhabitants (EVTCAP-PTGCAP), TREND and GDPCAP, and environmental tax per capita and gross domestic production per capita (EVTCAP-GDPCAP) are as expected. However, others, such as $\mathrm{CO}_{2}$ emission per capita and energy patent (CDECAP-PTGCAP) and $\mathrm{CO}_{2}$ emission per capita and environmental tax per capita (CDECAP-EVTCAP) are not as expected. We should consider that correlation matrix presents the unconditional relation between variables. This means that the sign and significance situation could change when they are studied conditional on other variables.

A Fisher-type test was applied to check the stationarity of all variables. In the context of panel data, the Fisher-type test performs a unit root test for each panel individually and then combines the p-values from these tests to obtain an overall test to identify whether the panel series contains a unit root. The null hypothesis tested is that all panels contain a unit root. For a finite number of panels, the alternative hypothesis is that at least one panel has stationarity.

Table 3 shows results for a selection of Fisher-type unit root tests for all panels, based on augmented Dickey-Fuller tests. All tests rejected the null hypothesis and it is detected that all panels are stationary. 
Table 3. Fisher-type unit-root tests result

\begin{tabular}{|l|c|c|c|c|}
\hline Variable & \multicolumn{1}{|l|}{$\begin{array}{l}\text { Inverse } \\
\text { chi-squared }\end{array}$} & $\begin{array}{l}\text { Inverse } \\
\text { normal }\end{array}$ & $\begin{array}{l}\text { Modified inv. } \\
\text { logit }\end{array}$ \\
\hline LCDECAP & 102.4375 & -6.9248 & -7.1988 & 9.3516 \\
\hline LGDPCAP & 121.3020 & -7.2424 & -8.4251 & 11.7870 \\
\hline LPTGCAP & 154.5430 & -9.4482 & -11.0220 & 16.0784 \\
\hline LPTICAP & 108.2611 & -6.3102 & -7.1981 & 10.1035 \\
\hline LEVTCAP & 101.8071 & -6.5370 & -7.0435 & 9.2703 \\
\hline LREGENP & 79.0775 & -5.0988 & -5.2345 & 6.3359 \\
\hline LGDPCAP & 116.7426 & -7.0275 & -8.0665 & 11.1984 \\
\hline LREGENP & 60.1541 & -3.3450 & -3.3837 & 3.8929 \\
\hline LPTGCAP & 130.8208 & -8.4524 & -9.3066 & 13.0159 \\
\hline LPTICAP & 103.8467 & -5.6432 & -6.5478 & 9.5336 \\
\hline LEVTCAP & 63.0009 & -4.0403 & -4.0083 & 4.2604 \\
\hline GDPRENP & 87.7950 & -5.7567 & -5.9721 & 7.4613 \\
\hline GDPPTIP & 109.2815 & -6.1472 & -7.0694 & 10.2352 \\
\hline GDPENGP & 154.4527 & -9.4641 & -11.0214 & 16.0668 \\
\hline GDPEVTP & 93.2944 & -5.7185 & -6.2946 & 8.1713 \\
\hline RENPTGP & 152.1289 & -9.3607 & -10.8274 & 15.7668 \\
\hline RENPTIP & 63.3171 & -3.4676 & -3.5652 & 4.3012 \\
\hline RENEVTP & 74.5212 & -4.5670 & -4.8312 & 5.7477 \\
\hline PTGPTIP & 147.9147 & -9.2704 & -10.5574 & 15.2227 \\
\hline PTGEVTP & 93.9943 & -6.4550 & -6.5826 & 8.2616 \\
\hline
\end{tabular}

\subsection{Model specification and testing functional form}

The standard form of Environmental Kuznets Curve is defined as given in eq. 4. In order to evaluate the impact of renewable energy deployment and technological innovation in energy applications adopted with climate change mitigation and ICTs, we include the additional variables related to these parameters and test the functional form by comparing it with two quadratic equations, Model 1 and Model 2, in the logarithmic form as follows:

(4)

$$
\begin{aligned}
\ln \left(C O_{2} / P\right)_{i t}=\alpha_{o}+\beta_{1} \ln (G D P / P)_{i t}+\beta_{2}\left(\ln (G D P / P)_{i t}^{2}+\varepsilon_{i t}\right. \\
\ln Y_{i t}=\alpha_{0}+\sum_{j} \beta_{j} \ln X_{j i t}+1 / 2 \sum_{j} \beta_{j j}\left(\ln X_{j i t}\right)^{2}+\beta_{t} t+1 / 2 \beta_{t t} t^{2} \\
+\sum_{j} \sum_{k} \beta_{j \mathrm{k}} \ln X_{j i t} \ln X_{k i t}+\sum_{j} \beta_{j t} \ln X_{j i t} t+\varepsilon_{i t}
\end{aligned}
$$


These models are frequently used. The translog function has become more popular as it provides more flexibility (Corbo and Meller, 1979).

The Likelihood Ratio (LR) test is employed to select the best functional form (Johnston and DiNardo, 2007). The models are estimated in restricted and unrestricted forms and the test values are calculated. The null hypothesis will be rejected, if the ratio of the two $\ln L$ values is small. The LR test is calculated as:

$$
L R=-2 \ln \lambda=2\left[\ln \left(L\left(\hat{\beta}, \hat{\sigma}^{2}\right)\right)-\ln \left(L\left(\tilde{\beta}, \tilde{\sigma}^{2}\right)\right)\right\rfloor \sim \chi_{q}^{2}
$$

where the two $L(.,$.$) terms are attributed to the restricted and unrestricted maximum$ likelihood estimation methods. $\beta$ and $\sigma^{2}$ and the unknown parameters estimated. The results of the LR test for all three models are presented in Table 4. The translog functional form of Model 3 (i.e., our model as shown in eq. 6), in comparison with its restricted versions of Model 2 and Model 1, is the most appropriate model to estimate the relation.

Table 4. LR test for functional form

\begin{tabular}{|c|c|c|c|}
\hline & LR test & Critical value & Result \\
\hline Model 3 vs. Model 1 & 340.0098 & 14.611 & Model 3 accepted \\
\hline Model 2 vs. Model 1 & 221.1320 & 3.940 & Model 2 accepted \\
\hline Model 3 vs. Model 2 & 118.8778 & 1.145 & Model 3 accepted \\
\hline
\end{tabular}

We employed the Akaike Information Criterion (AIC) and the Bayesian Information Criterion (BIC), in order to compare the functional form of the model specifications. The AIC and BIC are two popular statistical measures to compare models. They are defined as follows:

$$
\begin{aligned}
& A I C=-2 \ln (L)+2 k \\
& B I C=-2 \ln (L)+\ln (N) k
\end{aligned}
$$

where $\mathrm{k}$ is the number of parameters estimated and $\mathrm{N}$ is the number of observations. AIC and BIC are measures that combine fit and complexity. Fit is measured by $-2 \ln (L)$; the larger the value, the worse the fit. Complexity is measured either by $2 k$ for AIC or $\ln (N) k$ for BIC. Among the two models fit on the same data, the model with the smaller value of information criterion is considered better (Stata Base Reference Manual, 2012). The results of AIC and BIC for comparing models are presented in Table 5.

Table 5. Model specification test

\begin{tabular}{|l|c|c|c|c|c|}
\hline Model & Observation & $\ln (\mathrm{L})$ & $\mathrm{df}$ & AIC & BIC \\
\hline Model 1 & 240 & 45.3051 & 18 & -54.6102 & 8.0412 \\
\hline Model 2 & 240 & 155.8711 & 28 & -255.7423 & -158.2844 \\
\hline Model 3 (TL) & 240 & 215.3100 & 43 & $-344.6200^{* *}$ & $-194.9525^{* *}$ \\
\hline
\end{tabular}


Based on the results, the model specified by the translog function, Model 3 , is selected because it has the smallest value in both AIC and BIC measurements.

\subsection{Estimation method and testing procedures}

This model is usually estimated using panel data. Most studies have estimated both fixed and random effect models. The fixed effects model, eq. 1, assumes that $\alpha_{i}$ and $\gamma_{t}$ are correlated with explanatory variables, but they are considered random in the random effects model. The least-squares dummy variable (LSDV) is then applied to estimate the fixed effects model. In the case of the random effects model, the residuals from the OLS are used to estimate the variances and the model parameters by the Generalized Least Squares (GLS) technique. If a correlation is found between $\alpha_{i}, \gamma_{t}$ and the explanatory variables, the random effects model is inconsistent, and only the fixed effects model can estimate the regression consistently (Mundlak, 1978; Hsiao, 2003). A Hausman (1978) test was used to conduct the choice between the fixed effects and random effects models to measure consistency. With the assumption that no other statistical problem exists, the fixed effect model is estimated consistently.

Our estimation method differs from most studies, because it uses FGLS to correct for heteroscedasticity and autocorrelation. Although sources of serious problems are heteroscedasticity and autocorrelation in residuals, no earlier studies presented diagnostic tests of models. Stern et al. (1996) identified that the heteroscedasticity problem is important if we are concerned with cross-sections. Many researchers (Cropper and Griffiths, 1994; Shafik, 1994; Westbrook, 1995; Horvath, 1997; Moomaw and Unruh, 1997; Suri and Chapman, 1997) estimated fixed effects models without presenting regression diagnostic tests. Stern (2002) estimated a decomposed EKC using a FGLS model. Suri and Chapman (1998), Aldy (2005), and Luzzati and Orsini (2005) obtained results employing the FGLS approach, in order to correct cross-sectional heteroscedasticity and serial correlation.

Based on the literature, correlation and heteroscedasticity in panel-data models will cause the results to be biased and less efficient. Stata implements a test for serial correlation in the idiosyncratic errors of a linear panel-data model as discussed by Wooldridge (2002). Drukker (2003) presented simulation evidence that this test has good size and power properties in a reasonable sample size. When we applied the Wooldridge test for serial correlation, the null hypothesis of no first-order autocorrelation was rejected. The result showed that the computed value for the F-test (33.107) exceeds the critical F-value.

The Woolridge test for serial correlation provides an alternative to the Wald test for models with the maximum likelihood method. As the Wald test requires fitting only one model (the unrestricted model), and it is computationally more attractive than likelihood-ratio testing. Hence, Wald test is used whenever feasible because the null-distribution of the LR test statistics is often more closely chi-squared distributed than the Wald test statistics are (Stata Quick Reference and Index, 2012). 
Since iterated GLS with only heteroscedasticity generates the maximum likelihood parameters, we are able to calculate a LR test by comparing the estimation of a model fitted with panel-level heteroscedasticity and a model without heteroscedasticity. Based on the result, the null hypothesis is rejected. Therefore, the presence of heteroscedasticity is detected. The computed value for LR test (152.13) exceeds the critical chi-square value obtained from the F-table at the chosen level of significance. Thus, in the presence of heteroscedasticity and serial autocorrelation, we applied FGLS to estimate our models. FGLS is even asymptotically more efficient than OLS and other estimators (Wooldridge, 2002).

\section{Analysis of the Results}

\subsection{Estimation results}

The estimation results for the models specified in eq. (4)-(6) are reported in Table $6 .^{2}$ The share of coefficients, which was estimated with a high significance level ( $p<0.01)$, is greater than 60 percent. If we consider a general significance of 0.05 , it will even be more than 70 percent. The variables used include: carbon dioxide per capita (CDECAP), GDP per capita (GDPCAP), contribution of renewable energy sources in total power generation (REGENP), number of energy patents (PTGCAP), number of ICT patents per million inhabitants (PTICAP), environmental tax per capita (EVTCAP), and time trend (TREND). All variables, trend excepted, have been considered in logarithmic values. The coefficient signs of to the variables renewable energy generation, energy patents, and environmental tax are, as expected, negative. The sign for the linear and square of energy patents is negative, but the second one is not significant.

Table 6. Feasible Generalized Least Squares (FGLS) estimation result

\begin{tabular}{|c|c|c|c|c|c|c|}
\hline \multirow{2}{*}{ Variables } & \multicolumn{2}{|c|}{ Model 1} & \multicolumn{2}{|c|}{ Model 2} & \multicolumn{2}{|c|}{ Model 3} \\
\hline & Coeff. & $\mathrm{P}>|\mathrm{z}|$ & Coeff. & $\mathrm{P}>|\mathrm{z}|$ & Coeff. & $\mathrm{P}>|\mathrm{z}|$ \\
\hline lnGDP/P (LGDPCAP) & -1.1481 & 0.000 & -2.0142 & 0.000 & -0.3272 & 0.328 \\
\hline$(\operatorname{lnGDP} / \mathrm{P})^{2}\left(\mathrm{LGDPCAP}^{2}\right)$ & 0.2078 & 0.000 & 0.3287 & 0.000 & 0.2897 & 0.000 \\
\hline lnRen/TPG (REGENP) & & & -0.0213 & 0.102 & -0.2662 & 0.001 \\
\hline$(\operatorname{lnRen} / \mathrm{TPG})^{2}$ & & & 0.0210 & 0.000 & 0.0458 & 0.000 \\
\hline lnPateng/P (PTGCAP) & & & -0.0103 & 0.000 & -0.4070 & 0.000 \\
\hline$(\operatorname{lnPateng} / \mathrm{P})^{2}$ & & & -0.0031 & 0.003 & -0.0032 & 0.191 \\
\hline lnPatict/P (PTICAP) & & & 0.0253 & 0.000 & 1.0393 & 0.000 \\
\hline$(\operatorname{lnPatict} / \mathrm{P})^{2}$ & & & -0.0054 & 0.000 & -0.0011 & 0.409 \\
\hline
\end{tabular}

\footnotetext{
2 For matters of sensitivity analysis, two alternative models were also estimated: First, a model using environmental tax divided by fossil fuel consumption as a proxy for tax rate and, second, a normalized model with the mean of variables were also tested. In order to conserve spaces, the results are not reported here but are available upon request.
} 


\begin{tabular}{|c|c|c|c|c|c|c|}
\hline \multirow{2}{*}{ Variables } & \multicolumn{2}{|c|}{ Model 1} & \multicolumn{2}{|c|}{ Model 2} & \multicolumn{2}{|c|}{ Model 3} \\
\hline & Coeff. & $\mathrm{P}>|\mathrm{z}|$ & Coeff. & $\mathrm{P}>|\mathrm{z}|$ & Coeff. & $\mathrm{P}>|\mathrm{z}|$ \\
\hline $\operatorname{lnEvt/P~(EVTCAP)~}$ & & & 0.1230 & 0.000 & -1.8355 & 0.000 \\
\hline$(\operatorname{lnEvt} / \mathrm{P})^{2}$ & & & -0.0415 & 0.000 & -0.1779 & 0.000 \\
\hline Trend (TREND) & & & 0.0357 & 0.000 & 0.1850 & 0.000 \\
\hline Trend $^{2}$ & & & -0.0024 & 0.000 & -0.0019 & 0.000 \\
\hline$(\operatorname{lnGDP} / \mathrm{P})(\operatorname{lnRen} / \mathrm{TPG})$ & & & & & 0.0986 & 0.000 \\
\hline$(\operatorname{lnGDP} / \mathrm{P})(\ln P a t e n g / P)$ & & & & & 0.1001 & 0.000 \\
\hline$(\operatorname{lnGDP} / \mathrm{P})(\ln P a t i c t / P)$ & & & & & -0.2860 & 0.000 \\
\hline$(\operatorname{lnGDP} / \mathrm{P})(\operatorname{lnEvt} / \mathrm{P})$ & & & & & 0.3762 & 0.000 \\
\hline (lnGDP/P)Trend & & & & & -0.0474 & 0.000 \\
\hline (lnRen/TPG)(lnPateng/P) & & & & & -0.0077 & 0.039 \\
\hline$(\operatorname{lnRen} / \mathrm{TPG})(\operatorname{lnPatict} / \mathrm{P})$ & & & & & 0.0044 & 0.262 \\
\hline$(\operatorname{lnRen} / \mathrm{TPG})(\operatorname{lnEvt} / \mathrm{P})$ & & & & & -0.0178 & 0.389 \\
\hline (lnRen/TPG)Trend & & & & & -0.0092 & 0.000 \\
\hline (lnPateng/P)(lnPatict/P) & & & & & 0.0037 & 0.255 \\
\hline (lnPateng/P)(lnEvt/P) & & & & & -0.0901 & 0.000 \\
\hline (lnPateng/P)Trend & & & & & 0.0009 & 0.231 \\
\hline (lnPatict/P)(lnEvt/P) & & & & & 0.1994 & 0.000 \\
\hline (lnPatict/P)Trend & & & & & -0.0024 & 0.002 \\
\hline (lnEvt/P)Trend & & & & & 0.0205 & 0.000 \\
\hline Constant & 3.6722 & 0.000 & 5.0564 & 0.000 & -0.3071 & 0.625 \\
\hline Number of observations & 24 & & 24 & & 24 & \\
\hline Number of groups & 15 & & 15 & & 15 & \\
\hline Time periods & 16 & & 1 & & 16 & \\
\hline Wald chi-square & 516. & & 1389 & & 2549 & \\
\hline Prob > chi-square & 0.00 & & 0.00 & & 0.00 & \\
\hline
\end{tabular}

Considering the negative sign for the first order of GDP and positive sign for the second order, the relation between $\mathrm{CO}_{2}$ emissions and GDP shows a convex curve for the EU-15 countries. Regarding GDP, our result contrasts with early studies focused on the Environmental Kuznets Curve, which argued for the inverted U-shaped curve relationship between emission per capita and GDP per capita in developed countries. The U-shaped curve might be due to the fact that our sample consists of only advanced economies where all countries have reached the turning points and an additional increase in their welfare can be achieved only a higher environmental cost. The U-shaped curve relationship between environmental quality, level of 
income, and other variables was tested and analyzed by several researchers (Shafik, 1992; Panayotou, 1993, 1997; Selden and Song, 1994; Torras and Boyce, 1998; Suri and Chapman, 1998). Based on their findings, there may be a willingness to accept a weak level of environmental quality in the early stage of development, but a turning point will be achieved as the level of income increases.

However, this concept was challenged recently by researchers, such as Harbaugh et al. (2002) and Millimet et al. (2003). Wagner (2008) claimed that the evidence of an inverted U-shaped relationship between carbon emission and GDP obtained with commonly used methods is entirely spurious because of several major econometric problems. In line with this approach, we cast doubt on the results achieved by previous research using a simple model formulation and use a conditional model including several control variables. As Dasgupta et al. (2004) pointed out, the less robust relationship between GDP and $\mathrm{CO}_{2}$ emissions caused some econometric critiques; therefore, this relationship is not robust as found by previous researchers. Moreover, the role of GDP growth in $\mathrm{CO}_{2}$ emission reduction could be affected by the governance related explanatory variables.

Our estimation result shows an increase in decreasing rate of $\mathrm{CO}_{2}$ emissions in relation to the variables of energy patents and environmental tax. Furthermore, considering that we estimated our model from 1995 to 2010, and the financial crisis occurred within this period, the EU countries had to reduce expenditures for renewable energy, and coal-fueled power plants restarted operations because of the lower unit cost compared with imported crude oil and natural gas. In addition, the recession in the early 2000s should be taken into account. It was a downtrend in economic activity, which mainly happened in developed countries. The EU was affected by this recession from 2000 to 2002. Therefore, all indicators, including GDP, number of patents, taxes, and $\mathrm{CO}_{2}$ emissions could be affected by the recession in the early 2000s and the 2008 financial crisis.

Our result shows a concave formation between carbon emissions per capita (CDECAP) as dependent variable and GDP per capita (GDPCAP) and the share of renewable energy sources in total power generation (REGENP). It defines a decrease in the decreasing rate of carbon emissions regarding GDP and renewable energy in the EU-15.

The results in Table 6 also showed a convex formation between carbon emissions per capita (CDECAP), the number of ICT patents per million inhabitants (PTICAP), and technological change over time (TREND). Therefore, the results showed a decrease in the increasing rate of carbon emissions in relation to ICT patents and technological change over time. Furthermore, there is a convex formation between carbon emission per capita (CDECAP), energy patent applications per million inhabitants (PTGCAP), and environmental tax per capita (EVTCAP). The results showed an increase in the decreasing rate of carbon emissions in relation to the variables of energy patents and environmental tax.

ICT patents showed relevant positive and negative effects on $\mathrm{CO}_{2}$ emissions in different ways: The positive effects were increased electronic wastes, and the negative effects were improved 
energy efficiency. The impact of ICT on emissions was closely related to energy consumption (Hilty et al., 2006). The main increase in effects was caused by freight transport and ICT's demand for electricity in manufacturing and the disposal of hardware. Energy saving is made by virtual goods, ICT-supported management and ICT-supported control of the production process. Regarding the relationship between ICT patents and $\mathrm{CO}_{2}$ emissions, the results showed higher ICT patent growth with lower emission increases over time. Our findings are consistent with Romm et al. (2002), which argued that recent reductions in energy intensity were related to IT growth which were less energy intensive and increased efficiency in every other sectors of the economy.

The results showed that carbon emission is reduced through power generated by renewable energy sources. There is an extensive literature regarding the potential of carbon saving using renewable energy technologies. However, the reductions made by renewable energy enhancement have been decreased from 1995 to 2010 in the EU-15. The employment trend in renewable energy has been affected worldwide by global recession, policy changes, and overcapacities in the wind and solar supply chains (Martinot and Sawin, 2012). Therefore, the decreasing rates in the effectiveness of renewable energy could be explained by the reduction in the growth rate of renewable energy deployment.

Based on the findings, the impact of environmental tax on carbon emission has increased over time. This is consistent with the results obtained by Alfsen et al. (1995) regarding the sizable effects of carbon tax on emissions in Western Europe. They indicated that external benefits, such as reduction in health damage, damage to nature, and road traffic, are associated with carbon and energy taxes. Our findings are also consistent with Brännlund and Nordström (2004), who studied the effects of $\mathrm{CO}_{2}$ tax in Sweden. They found that demand for all fossil fuel-related goods was decreasing because of the $\mathrm{CO}_{2} \operatorname{tax}$.

The number of patents of energy technology for mitigation or adaptation to climate change had a similar impact on carbon emission compared with environmental tax. This is consistent with Popp (2001, 2005), who argued that it is important to consider the role of technological innovation in considering solutions to long-term environmental problems, such as energy consumption and climate change. Furthermore, according to Nordhaus (2002), it is expected that energy saving and energy efficiency induced innovation would lead to a reduction in carbon intensity per unit of output, but the cumulative effect might be larger in the long term.

Time trend showed a decreasing rate of carbon emission per capita. It indicated that the growth rate of carbon emission is reduced over time. The amount of $\mathrm{CO}_{2}$ is increasing; because the amount of production and consumption is increasing. However, the rate is decreasing because of the effects of technological change, productivity, and energy use efficiency. This finding is consistent with Popp (2005), who investigated the gradual process of the diffusion and adoption of new technologies. It is also consistent with the implications of energy efficiency technologies for climate policy, as discussed by Jaffe et al. (2001, 2003). 


\subsection{Elasticities of GDP, renewable energy generation, patents and environmental tax}

These elasticities measure the percentage change in emissions caused by a percent change in each variable. The derivative of eq. 6, presented in Table 6, with respect to the determinants of CO2 emission, called elasticities are calculated as:

$$
E_{j i t} \quad \partial \ln Y_{i t} / \partial \ln X_{j i t}=\beta_{j}+\sum_{k} \beta_{j k} \ln X_{k i t}+\beta_{j t} t
$$

Although the parameters in the translog function do not have a direct interpretation, they show the formation of a relationship between dependent and explanatory variables. In addition to this, we can easily calculate the elasticity of carbon emission with respect to GDP, renewable energy generation and environmental tax.

The elasticity of carbon emission for EU-15 countries over the period of 1995-2010 is calculated as $0.238,-0.165$, and 0.267 for GDP (GDPCAP), renewable energy generation (REGENP), and environmental tax (EVTCAP), respectively.

The results showed that the elasticity for each variable is affected by the other variables because of the interactive parameters. Therefore, elasticity is positive for environmental tax, whereas its coefficient is negative and strongly significant in our model. Generally, we face this situation when the translog function is applied. If model 1 were to be employed to estimate the relation, we could have expected a negative sign for the variables. However, this did not occur in the translog function because of the interaction relationship between the explanatory variables. The advantage of the translog function, compared with the other models, is its ability to evaluate these interactions representing complementarity and substitution between the variables.

In addition to interaction effects, the positive sign of environmental tax could be explained by the level of tax and its impact on consumer revenue. The EU-15 countries are considered developed countries, and their GDP per capita is relatively high. Therefore, the tax rate should be high enough to cause a sensitive reduction in energy consumption. This finding is consistent with Pearce (1991), who showed that a reduction in carbon emission may not be achieved unless the related elasticities are known with acceptable certainty. Moreover, Howarth (2006) pointed out that private consumption generates negative externality from increasing standard of living. Hence, we can argue that environmental tax has a negative effect on carbon emission indirectly by making an incentive to enhance renewable energy development or to create technological innovation. Tax revenues can cause an increase in household energy consumption through the revenue recycling effect, in which public revenues are used to reduce the tax rate on income and thereby provide increased transfer payments to households.

\subsection{Elasticities of technological change}

Regarding the elasticity of $\mathrm{CO}_{2}$ emissions in relation to energy and patent applications, the 
results showed that ICT and technology patents and trends were $-0.0249,0.005$, and -0.002 respectively. Our findings are consistent with the literature regarding the links between environmental regulation, innovation and technological change (Lanjouw and Mody 1996; Buonanno et al., 2003; Popp, 2006). The elasticities showed that energy patent applications that adopted climate change mitigation caused a reduction of 0.02 percent in carbon emissions per capita for an increase of 1.0 percent in the number of patents per one million inhabitants. Elasticity for trend, assumed as technological change, implies a negative, small impact on carbon emissions. The elasticity of ICT patents was positive and small, around 0.01 , which can be considered an effective parameter in climate change mitigation. This result is consistent with Fuchs (2008), and confirms that ICT sector emits less $\mathrm{CO}_{2}$ compared with average sector of the total economy. Fuchs indicated that the ICT sector constitutes a small portion of total value added and the most dominant economic activity in modern industrialized economies is fossil fuel combustion. The elasticities confirm this viewpoint, and the numbers vary across the countries.

\subsection{Variations in elasticities over time}

The variation in elasticities of $\mathrm{CO}_{2}$ emissions per capita in the EU-15 countries over time are presented in Table 7 . The time trend shows that effectiveness of renewable energy generation, innovation, and technological change on carbon emission reduction has improved steadily. There is a negative elasticity for GDP from 2001 to 2002, which could be explained by the recessions in Europe in the early 2000s.

Table 7. $\mathrm{CO}_{2}$ elasticities in the EU-15 countries over 1995-2010

\begin{tabular}{|c|c|c|c|c|c|c|}
\hline Year & GDPCAP & REGNEP & PTGCAP & PTICAP & EVTCAP & TREND \\
\hline 1995 & 0.6171 & -0.1133 & -0.0173 & 0.0010 & 0.0740 & 0.0284 \\
1996 & 0.5471 & -0.1220 & -0.0204 & 0.0077 & 0.1045 & 0.0251 \\
1997 & 0.3783 & -0.1300 & -0.0226 & 0.0160 & 0.1530 & 0.0225 \\
1998 & 0.3058 & -0.1301 & -0.0241 & 0.0190 & 0.1997 & 0.0178 \\
1999 & 0.1929 & -0.1443 & -0.0244 & 0.0214 & 0.2539 & 0.0146 \\
2000 & 0.0436 & -0.1569 & -0.0234 & 0.0219 & 0.2779 & 0.0122 \\
2001 & -0.0370 & -0.1697 & -0.0243 & 0.0241 & 0.3014 & 0.0092 \\
2002 & -0.0195 & -0.1920 & -0.0237 & 0.0214 & 0.3074 & 0.0062 \\
2003 & 0.1044 & -0.1845 & -0.0235 & 0.0083 & 0.3322 & -0.0025 \\
2004 & 0.2021 & -0.1784 & -0.0258 & 0.0025 & 0.3301 & -0.0095 \\
2005 & 0.1798 & -0.1850 & -0.0269 & 0.0010 & 0.3396 & -0.0139 \\
2006 & 0.2031 & -0.1854 & -0.0281 & -0.0043 & 0.3320 & -0.0195 \\
2007 & 0.3039 & -0.1830 & -0.0272 & -0.0165 & 0.3267 & -0.0265 \\
2008 & 0.3250 & -0.1794 & -0.0274 & -0.0224 & 0.3337 & -0.0325
\end{tabular}




\begin{tabular}{|c|c|c|c|c|c|c|}
\hline Year & GDPCAP & REGNEP & PTGCAP & PTICAP & EVTCAP & TREND \\
\hline 2009 & 0.2090 & -0.1906 & -0.0303 & -0.0107 & 0.3233 & -0.0335 \\
2010 & 0.2558 & -0.1920 & -0.0286 & -0.0063 & 0.2792 & -0.0356 \\
\hline Mean & 0.2382 & -0.1648 & -0.0249 & 0.0053 & 0.2668 & -0.0023 \\
\hline Std dev & 0.1793 & 0.0277 & 0.0033 & 0.0147 & 0.0869 & 0.0223 \\
\hline
\end{tabular}

The results showed that the elasticity of carbon emission per capita for tax has an upward trend, which is consistent with previous findings about the effects of environmental tax, interaction, and revenue recycling. The general trend of elasticities for renewable energy, energy patents, ICT patents, and trend steadily shows increased effectiveness in climate change mitigation (not reported here). In both models, the sign of environmental tax elasticity is negative. However, the sign of renewable energy is positive in the model where all variables are normalized with their sample mean.

\subsection{Variation in elasticities by country}

Table 8 presents the elasticities of $\mathrm{CO}_{2}$ emission per capita to GDP per capita (GDPCAP), share of electricity generated by renewable energy (REGNEP), energy patents application (PTGCAP) and ICT patents per one million inhabitants (PTICAP), environmental tax per capita (EVTCAP), and trend (TREND) in the EU-15 from 1995 to 2010 by country. The elasticities vary across countries, which can be explained by different demography, geography, economic structure, and policies of the member countries.

Table $8 . \mathrm{CO}_{2}$ elasticities in the EU-15 by country

\begin{tabular}{|l|c|c|c|c|c|c|}
\hline Country & GDPCAP & REGNEP & PTGCAP & PTICAP & EVTCAP & TREND \\
\hline Austria & 0.3186 & -0.0187 & -0.0178 & -0.0373 & 0.3358 & -0.0228 \\
Belgium & -0.1164 & -0.3010 & 0.0187 & -0.0697 & 0.4787 & 0.0042 \\
Germany & 0.8316 & -0.2425 & -0.2009 & 0.3898 & -0.3302 & 0.0389 \\
Denmark & 0.7046 & -0.1485 & -0.0666 & 0.0620 & 0.0807 & -0.0032 \\
Spain & 0.1419 & -0.1556 & 0.0161 & -0.0659 & 0.1926 & -0.0033 \\
Finland & -0.0791 & -0.0948 & -0.0275 & 0.0048 & 0.5251 & -0.0127 \\
France & -0.0662 & -0.1719 & 0.0119 & -0.0721 & 0.4778 & -0.0092 \\
Greece & 0.2423 & -0.2387 & -0.0001 & -0.0090 & -0.0552 & 0.0150 \\
Ireland & 0.2294 & -0.2107 & 0.0123 & -0.0728 & 0.4247 & -0.0066 \\
Italy & 0.2449 & -0.1474 & -0.0217 & 0.0054 & 0.1975 & -0.0014 \\
Luxembourg & 1.0530 & -0.0381 & -0.0156 & -0.0822 & 0.2663 & -0.0322 \\
Netherlands & 0.0437 & -0.2401 & -0.0327 & 0.0270 & 0.4054 & 0.0041 \\
Portugal & 0.4437 & -0.1417 & -0.0286 & 0.0463 & -0.2309 & 0.0122
\end{tabular}




\begin{tabular}{|l|c|c|c|c|c|c|}
\hline Country & GDPCAP & REGNEP & PTGCAP & PTICAP & EVTCAP & TREND \\
\hline Sweden & 0.1644 & -0.0433 & -0.0281 & -0.0128 & 0.4528 & -0.0205 \\
UK & -0.5830 & -0.2787 & 0.0075 & -0.0346 & 0.7806 & 0.0023 \\
\hline Mean & 0.2382 & -0.1648 & -0.0249 & 0.0053 & 0.2668 & -0.0023 \\
\hline Std dev & 0.4078 & 0.0883 & 0.0541 & 0.1158 & 0.2996 & 0.0172 \\
\hline
\end{tabular}

\subsection{Policy implication of the results for developing countries}

Our findings could be used by countries that attempt to develop eco-cities, such as Dongtan City in China and Masdar City in the UAE. Masdar City is supposed to rely entirely on solar energy and other renewable energy sources. Because of the wide range of strategies in different countries, which we have already analyzed, there is a good opportunity for the UAE government to take advantage of our findings to formulate policies to promote renewable energy in Masdar City. It is possible for the government to apply efficient energy policies at the starting point. The buildings of Masdar City are going to utilize energy-efficient construction material (Premalatha et al., 2013). Targets must be set and policies should be formulated to achieve these targets. For example, although European countries applied feedin-tariff (FIT) policies to develop renewable energy sources, they are now trying to build a harmonized market for renewable energy.

Al-Amir and Abu-Hijleh (2013) investigated the strategies used in different countries, in order to determine the best practical policy to apply in the UAE. As we pointed out, it is necessary to consider the effects of different variables on carbon emission reduction and the effects of their interactions. In other words, we should use a top-down approach to design a policy for climate change mitigation. We can then apply a bottom-up approach to select competitive technology in order to achieve the target. According to Al-Amir and Abu-Hijleh, a combination of FIT, RPS, and tax incentive policies should be applied by the government. Based on our findings, all elasticities should be known and reliable, in order to formulate an effective policy. A tax policy will not be effective, if it does not set taxes high enough to provide incentives to eliminate fossil-fuels products.

\section{Summary, Conclusion and Policy Recommendation}

In this study, we evaluated the impact of renewable energy development on carbon emission reduction. We also investigated the effectiveness of innovation in energy technologies for reducing carbon emissions, ICT technologies, and environmental taxes applied to encourage renewable energy development. Environmental tax was considered in the model, in order to evaluate the effects of market regulation. Several scholars have applied different methodologies to examine the relationship between energy consumption and economic growth in individual and groups of countries with respect to governmental energy policies. The relationship between carbon emissions and economic growth has been studied by many 
researchers using the Environmental Kuznets Curve. These studies analyzed variables, such as population, inequality, trade, and openness. Most results showed that environmental quality would be promoted after a certain level of economic growth is achieved. Therefore, developed countries with a high level of GDP per capita would promote environmental quality.

Recently, this idea has been challenged by theoretical and econometric critiques. Recent studies have shown that the methodology used by previous researchers was not appropriate to estimate this relationship. Moreover, the important role of governance-related variables was neglected. Our contribution to the literature is to add electricity generated by renewable energy sources, innovation in energy technology patent, ICT, and environmental tax to the model. All these variables are considered governance-related, either directly or indirectly. Environmental tax applied by governments is an example of the direct effect of governance. On the other hand, carbon emission is indirectly affected by governmental policy through technological innovation and renewable energy generation. Furthermore, we applied the FGLS method to estimate the model, in order to avoid major econometric problems.

In contrast to previous research, we found that economic growth might not lead to promoting environmental quality. The results showed a positive relation between carbon emission and GDP per capita in the EU-15, which are considered developed countries. Previous research found a negative relation between these variables. In popular myths about the effects of ICT technological innovation and environmental tax, both factors negatively affect carbon emission. However, our results showed that the impact of ICT differs across countries based on their structure. Environmental tax had a negative and strong effect on carbon emission by itself but the positive elasticity showed that its negative effect becomes positive because of high income and revenue recycling effects of tax policy.

In summary, we consider that the role of governmental policymaking is more important than economic growth. Renewable energy sources have been promoted in the EU-15 because of governmental supporting mechanisms and subsidies. Environmental tax policy and tightened standards could lead to more patents. Therefore, carbon emission will be more affected by governmental-related parameters than by achieving a certain level of economic development. This result could be important for the climate change policies of developing countries. In other words, it is not necessary to obtain a high level of economic growth, in order to enhance a country's environmental quality. Developing countries are able to achieve this target through appropriate policy making by their governments. Hence, developing countries could achieve high levels of environmental quality before achieving high levels of GDP per capita. 


\section{References}

Akarca, A. T., \& Long, T. V. (1980). Relationship between energy and GNP: a reexamination. Journal of Energy and Development 5(2), 326-331.

Al-Amir, J., \& Abu-Hijleh, B. (2013). Strategies and policies from promoting the use of renewable energy resource in the UAE. Renewable and Sustainable Energy Reviews, 26(0), 660-667.

Aldy, J. E. (2005). An environmental Kuznets curve analysis of US state-level carbon dioxide emissions. The Journal of Environment \& Development, 14(1), 48-72.

Alfsen, K. H., Birkelund, H., \& Aaserud, M. (1995). Impacts of an EC carbon/energy tax and deregulating thermal power supply on $\mathrm{CO} 2, \mathrm{SO} 2$ and NOx emissions. Environmental and Resource Economics, 5(2), 165-189.

Allen, E. L., Cooper, C., Edmonds, F., Edmonds, J., Reister, D., Weinberg, A., Zelby, L. (1976). US energy and economic growth, 1975-2010: Institute for Energy Analysis, Oak Ridge, Tenn.(USA).

Baltagi, B. (2008). Econometric analysis of panel data: John Wiley and Sons.

Benitez, L. E., Benitez, P. C., \& Van Kooten, G. C. (2008). The economics of wind power with energy storage. Energy Economics, 30(4), 1973-1989.

Bartelmus, P. (2013). The future we want: Green growth or sustainable development?, Environmental Development, 7, 165-170.

Bhattacharyya, S. C. (2011). Energy Economics: Concepts, Issues, Markets and Governance: Springer.

Brännlund, R., \& Nordström, J. (2004). Carbon tax simulations using a household demand model. European Economic Review, 48(1), 211-233.

Buonanno, P., Carraro, C., \& Galeotti, M. (2003). Endogenous induced technical change and the costs of Kyoto. Resource and Energy Economics, 25(1), 11-34.

Cameron, A. C., \& Trivedi, P. K. (2009). Microeconometrics using STATA (Vol. 5): Stata Press College Station, TX.

Cheng, B. S. (1995). An investigation of cointegration and causality between energy consumption and economic growth. Journal of Energy and Development, 21(1), 73-84.

Choi, E., Heshmati, A., \& Cho, Y. (2011). An empirical study of the relationships between CO2 emissions, economic growth and openness. Korean Journal of Environmental Policy 10(4), 3-37.

Coondoo, D., \& Dinda, S. (2002). Causality between income and emission: a country groupspecific econometric analysis. Ecological Economics, 40(3), 351-367.

Corbo, V., \& Meller, P. (1979). The translog production function: Some evidence from 
establishment data. Journal of Econometrics, 10(2), 193-199.

Dasgupta, S., Hamilton, K., Pandey, K., \& Wheeler, D. (2004). Air pollution during growth: accounting for governance and vulnerability. World Bank Policy Research Working Paper 3383.

Depuru, S. S. S. R., Wang, L., \& Devabhaktuni, V. (2011). Smart meters for power grid: Challenges, issues, advantages and status. Renewable and Sustainable Energy Reviews, 15(6), 2736-2742.

Drukker, D. M. (2003). Testing for serial correlation in linear panel-data models. Stata Journal, 3(2), 168-177.

Faruqui, A., Hledik, R., Newell, S., \& Pfeifenberger, H. (2007). The power of 5 percent. The Electricity Journal, 20(8), 68-77.

Ford, A. (1995). The impacts of large scale use of electric vehicles in southern California. Energy and Buildings, 22(3), 207-218.

Frankl, P., Masini, A., Gamberale, M., \& Toccaceli, D. (1997). Simplified life-cycle analysis of PV systems in buildings: present situation and future trends: INSEAD, Centre for the Management of Environmental Resources.

Fuchs, C. (2008). The implications of new information and communication technologies for sustainability. Environment, Development and Sustainability, 10(3), 291-309.

Galinato, G. I., \& Yoder, J. K. (2010). An integrated tax-subsidy policy for carbon emission reduction. Resource and Energy Economics, 32(3), 310-326.

Grossman, G. M., \& Krueger, A. B. (1991). Environmental impacts of a North American free trade agreement. National Bureau of Economic Research Working Paper No. 3914.

Harbaugh, W. T., Levinson, A., \& Wilson, D. M. (2002). Reexamining the empirical evidence for an environmental Kuznets curve. Review of Economics and Statistics, 84(3), 541551.

Hartway, R., Price, S., \& Woo, C. (1999). Smart meter, customer choice and profitable timeof-use rate option. Energy, 24(10), 895-903.

Hausman, J. A. (1978). Specification tests in econometrics. Econometrica: Journal of the Econometric Society, 1251-1271.

Hilty, L. M., Arnfalk, P., Erdmann, L., Goodman, J., Lehmann, M., \& Wäger, P. A. (2006). The relevance of information and communication technologies for environmental sustainability - A prospective simulation study. Environmental Modelling \& Software, 21(11), 1618-1629.

Hitch, C. J. (1978). Energy conservation and economic growth.

Howarth, R. B. (2006). Optimal environmental taxes under relative consumption effects. Ecological Economics, 58(1), 209-219. 
Hsiao, C. (2003). Analysis of panel data (Vol. 34): Cambridge University Press.

Huang, B.-N., Hwang, M., \& Yang, C. (2008). Causal relationship between energy consumption and GDP growth revisited: a dynamic panel data approach. Ecological Economics, 67(1), 41-54.

IEA. (2012). CO2 Emissions from Fuel Combustion 2012: OECD Publishing.

Jackman, S. (2004). Generalized Least Squares: Stanford University.

Jaffe, A. B., Newell, R. G., \& Stavins, R. N. (2001). Energy-efficient technologies and climate change policies. Climate Change Economics and Policy: An RFF Anthology, 171.

Jaffe, A. B., Newell, R. G., \& Stavins, R. N. (2003). Technological change and the environment. Handbook of Environmental Economics, 1, 461-516.

Jaffe, A. B., \& Palmer, K. (1997). Environmental regulation and innovation: A panel data study. The Review of Economics and Statistics, 79(4), 610-619.

Jansen, B., Binding, C., Sundstrom, O., \& Gantenbein, D. (2010). Architecture and communication of an electric vehicle virtual power plant. Paper presented at the 2010 First IEEE International Smart Grid Communications.

Johnston, J., \& DiNardo, J. (2007). Econometric methods (Vol. 4): Wiley Online Library.

Kempton, W., \& Letendre, S. E. (1997). Electric vehicles as a new power source for electric utilities. Transportation Research Part D: Transport and Environment, 2(3), 157-175.

Kempton, W., \& Tomić, J. (2005). Vehicle-to-grid power implementation: From stabilizing the grid to supporting large-scale renewable energy. Journal of Power Sources, 144(1), 280-294.

Kraft, J., \& Kraft, A. (1978). Relationship between energy and GNP. Journal of Energy and Development, 3(2), 401-403.

Kuznets, S. (1955). Economic growth and income inequality. The American Economic Review, 45(1), 1-28.

Lanjouw, J. O., \& Mody, A. (1996). Innovation and the international diffusion of environmentally responsive technology. Research Policy, 25(4), 549-571.

Lee, C.-C., \& Chang, C.-P. (2008). Energy consumption and economic growth in Asian economies: A more comprehensive analysis using panel data. Resource and Energy Economics, 30(1), 50-65.

Lehner, B., Czisch, G., \& Vassolo, S. (2005). The impact of global change on the hydropower potential of Europe: a model-based analysis. Energy Policy, 33(7), 839-855.

Li, J., \& Colombier, M. (2009). Managing carbon emissions in China through building energy efficiency. Journal of Environmental Management, 90(8), 2436-2447. 
Luzzati, T., \& Orsini, M. (2009). Investigating the energy-environmental Kuznets curve. Energy, 34(3), 291-300.

Magnani, E. (2000). The Environmental Kuznets Curve, environmental protection policy and income distribution. Ecological Economics, 32(3), 431-443.

Martinot, E., \& Sawin, J. (2012). Renewables Global Status Report: 2012 update.

Millimet, D. L., List, J. A., \& Stengos, T. (2003). The environmental Kuznets curve: Real progress or misspecified models? Review of Economics and Statistics, 85(4), 10381047.

Mundlak, Y. (1978). On the pooling of time series and cross section data. Econometrica: Journal of the Econometric Society, 69-85.

Narayan, P. K., \& Prasad, A. (2008). Electricity consumption-real GDP causality nexus: Evidence from a bootstrapped causality test for 30 OECD countries. Energy Policy, 36(2), 910-918.

Nordhaus, W. D. (2002). Modeling induced innovation in climate-change policy. Technological Change and the Environment, 182-209.

Oberthür, S., \& Roche Kelly, C. (2008). EU leadership in international climate policy: achievements and challenges. The International Spectator, 43(3), 35-50.

Panayotou, T. (1993). Empirical tests and policy analysis of environmental degradation at different stages of economic development: International Labour Organization.

Panayotou, T. (1997). Demystifying the environmental Kuznets curve: turning a black box into a policy tool. Environment and development economics, 2(4), 465-484.

Pearce, D. (1991). The role of carbon taxes in adjusting to global warming. The economic journal, 101(407), 938-948.

Popp, D. (2003). Pollution control innovations and the Clean Air Act of 1990. Journal of Policy Analysis and Management, 22(4), 641-660.

Popp, D. (2005). Lessons from patents: Using patents to measure technological change in environmental models. Ecological Economics, 54(2-3), 209-226.

Popp, D. (2006). International innovation and diffusion of air pollution control technologies: the effects of NOX and SO2 regulation in the US, Japan, and Germany. Journal of Environmental Economics and Management, 51(1), 46-71.

Popp, D., Hascic, I., \& Medhi, N. (2011). Technology and the diffusion of renewable energy. Energy Economics, 33(4), 648-662.

Popp, D. C. (2001). The effect of new technology on energy consumption. Resource and Energy Economics, 23(3), 215-239.

Premalatha, M., Tauseef, S., Abbasi, T., \& Abbasi, S. (2013). The promise and the 
performance of the world's first two zero carbon eco-cities. Renewable and Sustainable Energy Reviews, 25, 660-669.

Pudjianto, D., Ramsay, C., \& Strbac, G. (2007). Virtual power plant and system integration of distributed energy resources. Renewable power generation, IET, 1(1), 10-16.

Romm, J. (2002). The internet and the new energy economy. Resources, conservation and recycling, 36(3), 197-210.

Ruiz, N., Cobelo, I., \& Oyarzabal, J. (2009). A direct load control model for virtual power plant management. Power Systems, IEEE Transactions on, 24(2), 959-966.

Saner, D., Juraske, R., Kübert, M., Blum, P., Hellweg, S., \& Bayer, P. (2010). Is it only CO< sub $>2</$ sub $>$ that matters? A life cycle perspective on shallow geothermal systems. Renewable and Sustainable Energy Reviews, 14(7), 1798-1813.

Schleisner, L. (2000). Life cycle assessment of a wind farm and related externalities. Renewable Energy, 20(3), 279-288.

Schmalensee, R. (2012). From “green growth” to sound policies: An overview, Energy Economics, 34, 52-56.

Selden, T. M., \& Song, D. (1994). Environmental Quality and Development: Is There a Kuznets Curve for Air Pollution Emissions? Journal of Environmental Economics and Management, 27(2), 147-162.

Shafik, N., \& Bandyopadhyay, S. (1992). Economic growth and environmental quality: time series and cross country evidence. World Bank Policy Research Working Paper Series No. 904.

Sinha, A. (1993). Modelling the economics of combined wind/hydro/diesel power systems. Energy conversion and management, 34(7), 577-585.

Soytas, U., \& Sari, R. (2009). Energy consumption, economic growth, and carbon emissions: Challenges faced by an EU candidate member. Ecological Economics, 68(6), 16671675.

Stata Quick Reference and Index. (2012). Stata Press

Stern, D. I. (1998). Progress on the environmental Kuznets curve? Environment and development economics, 3(2), 173-196.

Stern, D. I. (2000). A multivariate cointegration analysis of the role of energy in the US macroeconomy. Energy Economics, 22(2), 267-283.

Stern, D. I. (2002). Explaining changes in global sulfur emissions: an econometric decomposition approach. Ecological Economics, 42(1-2), 201-220.

Stern, D. I., Common, M. S., \& Barbier, E. B. (1996). Economic growth and environmental degradation: The environmental Kuznets curve and sustainable development. World development, 24(7), 1151-1160. 
Suri, V., \& Chapman, D. (1998). Economic growth, trade and energy: implications for the environmental Kuznets curve. Ecological Economics, 25(2), 195-208.

Torras, M., \& Boyce, J. K. (1998). Income, inequality, and pollution: a reassessment of the environmental Kuznets Curve. Ecological Economics, 25(2), 147-160.

Wagner, M. (2008). The carbon Kuznets curve: A cloudy picture emitted by bad econometrics? Resource and Energy Economics, 30(3), 388-408.

Wolde-Rufael, Y. (2005). Energy demand and economic growth: The African experience. Journal of Policy Modeling, 27(8), 891-903.

Wooldridge, J. M. (2002). Econometric analysis of cross section and panel data: The MIT Press.

Yu, E. S., \& Hwang, B.-K. (1984). The relationship between energy and GNP: further results. Energy Economics, 6(3), 186-190.

Zhang, X.-P., \& Cheng, X.-M. (2009). Energy consumption, carbon emissions, and economic growth in China. Ecological Economics, 68(10), 2706-2712. 